\title{
APLICAÇÃO DAS FERRAMENTAS DA QUALIDADE EM UM AVIÁRIO DE FRANGO
}

\author{
Guilherme dos Reis (EPA, UNESPAR-FECILCAM, Brasil) alda.guilherme@gmail.com \\ Jordão Mazureka de Abreu (EPA, UNESPAR-FECILCAM, Brasil) jordao_07@hotmail.com \\ Lucas dos Santos (EPA, UNESPAR-FECILCAM, Brasil) lizicresi_lucas@hotmail.com \\ Roselis Natalina Mazzuchetti (EPA, UNESPAR-FECILCAM, Brasil) profbibi@hotmail.com \\ Rony Peterson da Rocha (EPA, UNESPAR-FECILCAM, Brasil) petersonccbpr@hotmail.com
}

\begin{abstract}
Resumo: O objetivo do trabalho é aplicar as ferramentas da Qualidade no aviário de frangos para identificar possíveis causas da mortalidade de frangos, buscando minimizar perdas e consequentemente maximizar lucros. Foram aplicadas ferramentas simples que demonstraram o problema durante o período de formação de um lote, 45 dias, por meio de gráfico de sequência. Os dados foram estratificados e as causas vitais foram separadas das triviais com a utilização do Diagrama de Pareto. Os dados revelaram que a causa principal da mortalidade foi o Descarte de frango por má formação genética. Utilizando o Diagrama de Ishikawa, por meio de brainstorming, observou-se que as causas que afetam o problema, genética, matrizes novas e distância do matrizeiro da propriedade, são geradas pelo fornecedor que fornece os pintinhos. E, portanto, incontrolável pela propriedade em estudo. A sugestão para solucionar o problema foi de mudança de fornecedor ou maior intervenção com o fornecedor atual para melhoria do produto. Espera-se que este estudo forneça subsídio para busca de solução de problemas em diversos setores, lembrando que ferramentas podem e devem ser adicionadas para maior precisão da informação. Palavras-chave: Ferramentas da qualidade. Avicultura. Mortalidade.
\end{abstract}

\section{Introdução}

Com o mercado cada vez mais exigente, empresas rurais se adaptam a essas exigências e buscar cada vez mais investir em alternativas com o objetivo de melhorar a qualidade de seus produtos.

O objetivo do trabalho é aplicar as ferramentas da Qualidade no aviário de aves para identificar possíveis causas da mortalidade de frangos, buscando minimizar perdas e consequentemente maximizar lucros e ainda propor melhorias. A empresa em estudo é um aviário com capacidade de trinta e três mil (33.000) frangos por lote, se situa na zona rural de Ubiratã-PR estrada Olinda. $\mathrm{O}$ artigo possui a seguinte estrutura: referencial teórico, metodologia, resultados e discussão e conclusão. 


\section{Revisão literária}

\subsection{Definições de qualidade}

Existem algumas definições para a Qualidade em si. Para defini-la serão utilizados alguns autores considerados "gurus da qualidade". Juran "define qualidade como adequação ao uso". Já Deming diz "qualidade de um produto ou serviço apenas pode ser definida pelo cliente", sendo assim muito relativo. E para finalizar, Ishikawa entrou com o conceito de "círculos da qualidade" definindo-o como sendo "pequenas equipes, geralmente da mesma área de trabalho, que voluntária e regularmente se reúnem para identificar, investigar, analisar e resolver os problemas que surgem no trabalho" (CHASE et al., 2004)

Este trabalho enquadra-se, segundo a ABEPRO (2008), dentre as áreas de conhecimento da Engenharia de Produção na área de Engenharia da Qualidade. Sendo descrita como "Planejamento, projeto e controle de sistemas de gestão da qualidade que considerem o gerenciamento por processos, a abordagem factual para a tomada de decisão e a utilização de ferramentas da qualidade." Quanto as subáreas de conhecimento relacionadas a Engenharia da Qualidade o presente trabalho apresenta seu foco, segundo a ABEPRO (2008), voltado para as Gestão de Sistemas da Qualidade.

\subsection{Ferramentas da qualidade}

São diversas as ferramentas utilizadas para o controle da qualidade que buscam observar, ordenar e analisar dados que permitam detectar aspectos cruciais para solução de problemas e melhorias de processos. Neste artigo apresentaremos apenas as ferramentas mais comuns, que permitem ser utilizadas em qualquer processo, sejam elas: Folha de Verificação, Estratificação, Gráfico de Pareto, Diagrama de Ishikawa. Tais ferramentas são comumente utilizadas na aplicação do PDCA que é uma sequência de atividades percorridas de maneira cíclica para um melhoramento da qualidade.

Slack et al. (1999) define o ciclo PDCA como, o conceito de melhoramento continua implica literalmente um processo sem fim, questionando e re-questionando os trabalhos detalhados de uma operação.

Montgomery (2004) colocam que o início do processo é a adoção da folha de verificação ou folha de controle, onde os dados são coletados. Ao planejar uma folha de controle, é importante especificar alguns claramente o tipo de dados a serem coletados, o numero da parte ou operação, a data, o analista, ou quais quer outros dados relevantes.

Godoy (2009) define Folha de Verificação como um meio bastante simples de coleta de dados. Trata-se de um instrumento simples contendo um conjunto de itens que podem aparecer em um processo, para o qual se deve verificar a ocorrência ou não.

A folha de estratificação consiste em agrupar os dados em diferentes extratos ou grupos, marca, sexo, turno, cidade. Godoy (2009) fala que a estratificação consiste no agrupamento da informação (dados), com uma ideia básica da estratificação. No entanto, os dados que estão sendo examinados necessitam ser prote- 
gidos de fatores originários que possam conduzir a diferentes características estatísticas.

O gráfico de Pareto é simplesmente uma distribuição de frequência (ou histograma) de dados atributos, organizados por categoria, mas o mesmo não identifica automaticamente os "defeitos" mais importantes (MONTGOMERY, 2004).

Já Slack et al. (1999) define o diagrama de Pareto como uma técnica relativamente direta, que envolve classificar itens informação nos tipos de problema ou causas de problemas por ordem de importância. Isso pode ser usado para destacar áreas onde investigações adicionais poderão ser úteis. A análise de Pareto é baseado no fenômeno que ocorre frequentemente de relativamente poucas causas explicariam a maioria dos defeitos.

Montgomery C. Douglas (2004) afirmam que uma vez que um defeito, erro ou problema tenha sido identificado para o estudo posterior devemos começar a analisar as causas potenciais desse efeito indesejável.

Segundo SLACK et al. (1999) os diagramas de causa-efeito são um método particularmente de ajuda a pesquisar raízes de problemas, ele faz isso levantando as questões: o que, onde, como, quando e porque. $\mathrm{O}$ procedimento para se desenhar um diagrama de causa-efeito segue os seguintes passos:

Passo 1: Coloque o problema na caixa "efeito";

Passo 2: Identifique as principais categorias para causas possíveis do problema;

Passo 3: Use a busca sistemática de fatos e discussões para gerar possíveis causas;
Passo 4: Registre todas as causas potenciais no diagrama sob cada categoria, e discuta cada item para combinar e esclarecer as causas.

Realizado isso é utilizado o método brainstorming (chuva de ideias) para identificar as causas e sub causas em cada uma das categorias escolhida.

Para determinar as causas que realmente provocam o efeito pode-se utilizar o método cientifico de Indução, Dedução e Verificação ou a técnica dos Porquês que indaga incansavelmente cada causa. Os resultados devem ser acompanhados de um plano de ação (SLACK et al., 1999).

\subsubsection{Produção de frango}

O mercado de carne de frango é muito promissor, fatores como preço e qualidade ajudaram a aumentar a produtividade no setor juntamente com investimento em tecnologias de manejo, melhoramento genético e instrumentos. Com alto potencial de crescimento, o Ministério da Agricultura estima que a produção de carne de frango no Brasil cresça quase $80 \%$ em dez anos. A expectativa é que a produção nacional de carne de frango passe de 13,2 milhões de toneladas no período atual para até $23,7 \mathrm{mi}$ lhões de toneladas em dez anos (O GLOBO, 2013).

$\mathrm{Na}$ produção de frango de corte, integração vertical ocorre quando uma empresa coordena todo o processo produtivo, fornecendo o pinto de um dia e todos os demais insumos utilizados na produção e assistência técnica. A estrutura 


\section{ReLAlnEP}

que abriga a produção é denominada de aviário. O melhor sistema é o Dark House.

O sistema possui comedouro automático, bebedouro nipple e exaustores em pressão negativa. $\mathrm{O}$ sistema de resfriamento pode ser por nebulização ou pad cooling. Possui forro de polietileno preto de um lado e preto ou claro do outro lado. Alguns produtores utilizam defletores no forro. Necessitam de controle de luz natural por meio de light-trap na entrada e saída do ar. Nesse sistema o controle da intensidade de luz é imprescindível e realizado por meio de dimmer. O uso de geradores de energia é indispensável. A cortina tem que ser bem vedada para não permitir entrada de ar, com vistas à maior eficiência do sistema de exaustão, sendo em polietileno preto de um lado e reflexiva do outro. Objetiva-se com esse sistema maior controle da iluminação e das condições térmicas ambientais no interior do aviário (ABREU; ABREU, 2011, p. 8).

O processo produtivo se inicia quando os pintos com um dia de vida é enviado para o produtor da incubadora via caminhões apropriados para o transporte, percorrendo distancias consideráveis até os aviários, onde ficaram alojados por cerca de 45 dias, quando os pintos chegam no aviário o próprio deve estar aquecido a $32^{\circ} \mathrm{C}$ (trinta e dois graus Celsius), para não ocorrer choque térmico nos pintos, dentro desses 45 dias o frango passa por 4 fases de ração, também fornecida pelo frigorífico que são elas a pré-inicial, inicial, desenvolvimento e final. O manuseio dos frangos durante o lote fica por conta do produtor. No termino dos 45 dias o frigorífico mandam caminhões gaiola para a retirada e transporte dos frangos até o frigorífico onde serem abatidos e industrializados. Após cada lote, deve-se deixar um tempo de 15 dias entre lotes para um vazio sanitário (RICHETTI; SANTOS, 2000).

Durante a produção ocorrem diversos problemas e um dos maiores problemas que gera prejuízo ao avicultor é a mortalidade. Segundo Heinzen (2006), o índice de mortalidade nas granjas gira entorno de 3\% do lote, o que está dentro do aceitável e visto em outras empresas. Quando ocorrem índices maiores o problema está na produção em si ou quando ocorrem problemas sanitários.

\section{Metodologia de pesquisa}

O método de abordagem utilizado para o desenvolvimento da pesquisa foi o qualitativo e quantitativo. Foram utilizados dados primários e secundários. Os dados primários foram coletados em um único lote entre os meses de abril e maio de 2013, por meio de Folha de Verificação.

Para a análise das variáveis ligadas ao problema mortalidade, foi utilizado o Gráfico de Sequencias, Diagrama de Pareto e o Diagrama de Ishikawa, também conhecido como Diagrama de Causa e Efeito ou Espinha de Peixe. Conforme Paladini (2000), tais ferramentas tem se mostrado eficazes para busca de solução de questões que influenciem negativamente o processo ou intensificam elementos que podem afetar de forma positiva um conjunto de operações. Para o desenvolvimento do Dia- 


\section{ReLAlnEP}

grama de Causa e Efeito foi utilizado o Brainstorming. Essa técnica propõe que um grupo de pessoas se reúna e se utilizem das diferenças em seus pensamentos e ideias para que possam chegar a um denominador comum eficaz e com qualidade. A análise dos dados foi nas formas quantitativa e qualitativa, sendo a apresentação na forma descritiva e por meio de tabelas e gráficos.

\section{Resultados e discussões}

O aviário em estudo é situado na zona rural de Ubiratã-PR, integrado a um frigorífico. Tratase de um aviário novo com 36 meses de operação, Sua estrutura é de alvenaria e coberto com telhas cotando com o sistema de produção Dark House.

O problema enfrentado na propriedade é a taxa de mortalidade de frangos, que por lote que pode chegar a 1.200 frangos, em torno de $4 \%$ do total de frangos do lote. Cabe lembrar que um lote de frangos é de 30000 unidades e a taxa de mortalidade geralmente aceita é de $3 \%$ do lote.

A produção na propriedade ocorre da maneira integrada vertical, começa com o contrato entre a agroindústria e avicultor, quando a agroindústria efetua o envio de pintos com um dia de vida dos matrizeiros, que se localiza na cidade de Dois Vizinhos-PR, distando 280 km da propriedade em estudo.

A partir dos pintos entregues o avicultor recebe suporte da agroindústria, que fornece ração para cada fase do pinto e assistência de um técnico até que eles atinjam os 45 dias, que é o tempo necessário para ganhar peso e porte para $\mathrm{o}$ abate.

Os frangos são retirados da propriedade por meio de caminhões gaiola terceirizado com pega manual dos frangos. Tais caminhões percorrem 279 km até a cidade de Rolândia-PR onde foram abatidos. Diante deste histórico, buscou-se identificar as possíveis causas da alta mortalidade do frango que ocorre no aviário e afetam a lucratividade do negócio.

Para tanto coletamos as informações referente a um lote que iniciou no mês de abril e prolongou-se ao mês de maio de 2013 por meio de uma Ficha de controle do aviário

(Folha de verificação ou folha de controle). Nesta ficha consta o número de mortes, as causa das mortes e o dia em que elas ocorreram como mostra a Tabela 1 . 


\section{ReLAlnEF}

TABELA 1: FOLHA DE VERIFICAÇÃO DAS MORTALIDADES OCORRIDAS NO AVIÁRIO

\begin{tabular}{|c|c|c|c|c|c|}
\hline Dia & Mortes & Coração & Descartes & Pernas & Total \\
\hline $18 / a b r$ & 30 & 0 & 30 & 12 & 72 \\
\hline 19/abr & 15 & 0 & 18 & 0 & 33 \\
\hline $20 / a b r$ & 20 & 0 & 0 & 18 & 38 \\
\hline $21 / a b r$ & 10 & 0 & 7 & 0 & 17 \\
\hline $22 / a b r$ & 10 & 0 & 10 & 2 & 22 \\
\hline 23/abr & 18 & 0 & 20 & 0 & 38 \\
\hline $24 / a b r$ & 20 & 10 & 0 & 9 & 39 \\
\hline $25 / a b r$ & 3 & 0 & 10 & 3 & 16 \\
\hline 26/abr & 4 & 0 & 10 & 0 & 14 \\
\hline $27 / a b r$ & 7 & 0 & 20 & 0 & 27 \\
\hline 28/abr & 3 & 0 & 10 & 0 & 13 \\
\hline 29/abr & 10 & 0 & 30 & 2 & 42 \\
\hline $30 / a b r$ & 5 & 0 & 20 & 0 & 25 \\
\hline 01/mai & 3 & 0 & 15 & 2 & 20 \\
\hline 02/mai & 10 & 0 & 30 & 0 & 40 \\
\hline 03/mai & 25 & 0 & 25 & 0 & 50 \\
\hline 04/mai & 15 & 0 & 60 & 0 & 75 \\
\hline 05/mai & 10 & 0 & 10 & 0 & 20 \\
\hline 06/mai & 10 & 0 & 11 & 0 & 21 \\
\hline 07/mai & 16 & 0 & 0 & 0 & 16 \\
\hline 08/mai & 2 & 0 & 10 & 0 & 12 \\
\hline 09/mai & 5 & 2 & 5 & 0 & 12 \\
\hline 10/mai & 4 & 4 & 15 & 0 & 23 \\
\hline 11/mai & 10 & 10 & 10 & 0 & 30 \\
\hline 12/mai & 4 & 5 & 18 & 0 & 27 \\
\hline 13/mai & 5 & 4 & 19 & 0 & 28 \\
\hline 14/mai & 2 & 1 & 10 & 3 & 16 \\
\hline 15/mai & 4 & 5 & 5 & 0 & 14 \\
\hline 16/mai & 5 & 5 & 10 & 0 & 20 \\
\hline 17/mai & 5 & 3 & 5 & 0 & 13 \\
\hline 18/mai & 5 & 5 & 10 & 0 & 20 \\
\hline 19/mai & 2 & 2 & 8 & 0 & 12 \\
\hline 20/mai & 2 & 2 & 9 & 0 & 13 \\
\hline 21/mai & 5 & 5 & 5 & 0 & 15 \\
\hline 22/mai & 10 & 5 & 10 & 0 & 25 \\
\hline 23/mai & 2 & 3 & 10 & 0 & 15 \\
\hline 24/mai & 5 & 5 & 0 & 2 & 12 \\
\hline
\end{tabular}

Revista Latino-Americana de Inovação e Engenharia de Produção Vol. 2, n. 3. jul./dez. 2014 


\section{ReLAInEP}

\begin{tabular}{cccccc}
\hline Dia & Mortes & Coração & Descartes & Pernas & Total \\
\hline 25/mai & 10 & 15 & 5 & 0 & 30 \\
26/mai & 10 & 10 & 5 & 0 & 25 \\
27/mai & 10 & 10 & 0 & 0 & 20 \\
28/mai & 10 & 10 & 10 & 5 & 35 \\
29/mai & 10 & 10 & 6 & 0 & 26 \\
30/mai & 10 & 10 & 3 & 0 & 23 \\
31/mai & 30 & 30 & 30 & 0 & 90 \\
\hline
\end{tabular}

Fonte: Dados da pesquisa

Para um melhor entendimento, utilizou-se o gráfico de controle ou de sequência para melhor visualizar as ocorrências de mortalidade durante o período (Gráfico 1).

Observa-se que ocorre alta mortalidade no início do processo, após 15 dias e no final da produção do lote. Como o resultado é muito vago e para melhor visualizar o problema utilizou-se a ferramenta "Estratificação", apresentado no Gráfico 2, ainda na sequência de tempo.

GRÁFICO 1: GRÁFICO DE CONTROLE DA MORTALIDADE DO LOTE

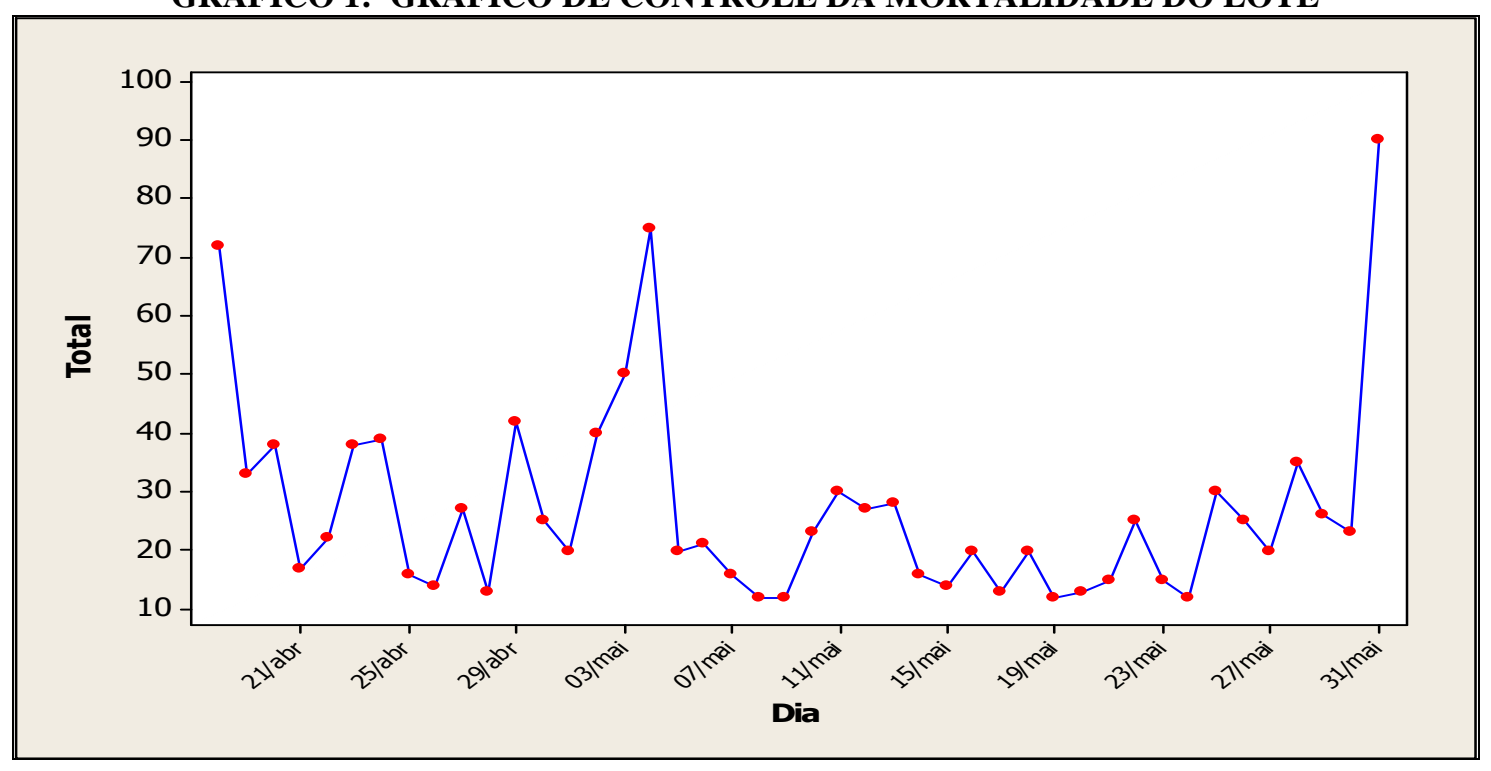

Fonte: Dados da pesquisa 
GRÁFICO 2: GRÁFICO DE SEQUÊNCIA POR TIPO DE MORTALIDADE

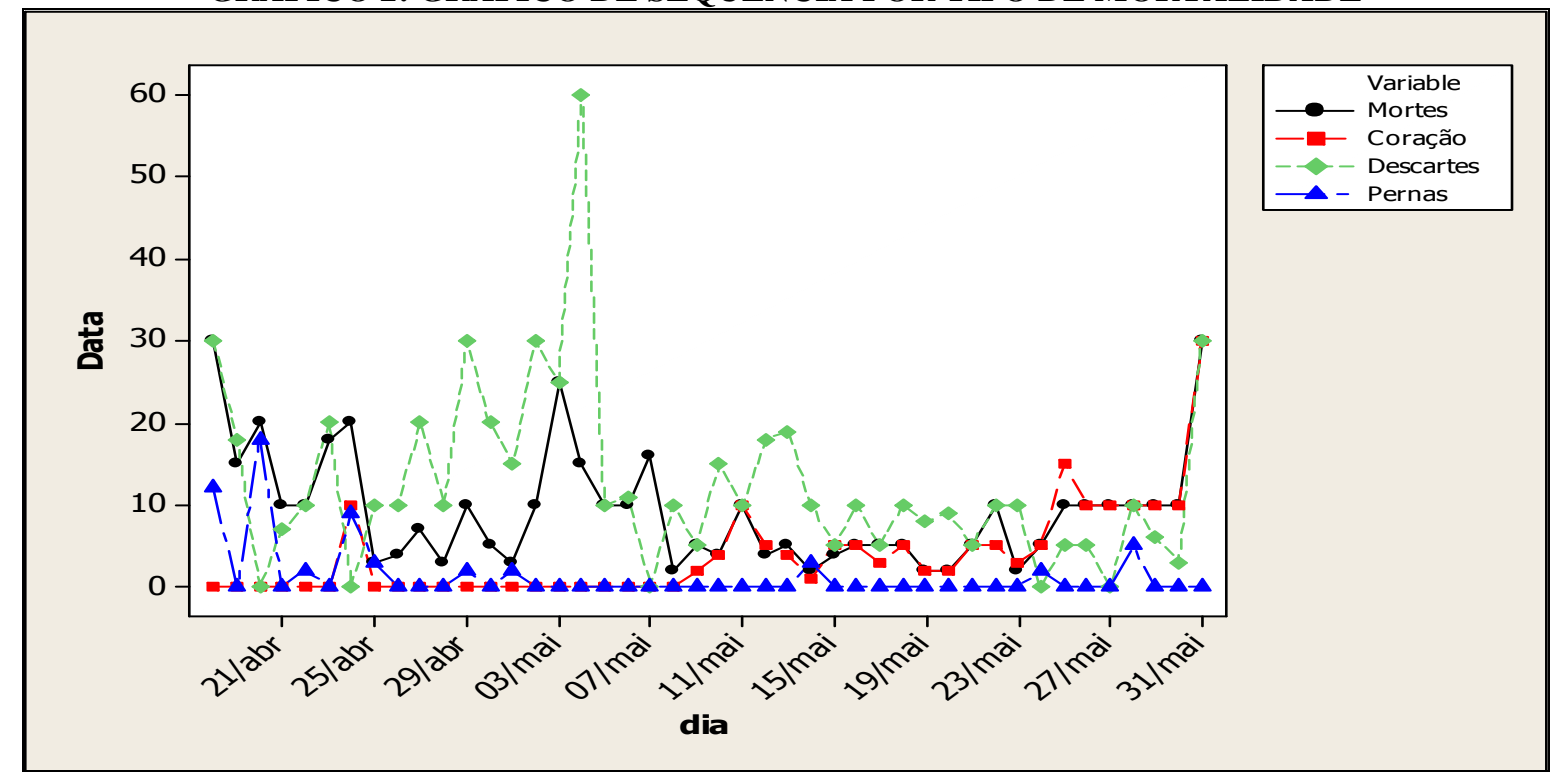

Fonte: Dados da pesquisa

A estratificação foi a considerada pelo próprio aviário, sendo elas: Mortes sem causas específicas, apresentada doravante simplesmente como "Mortes", morte por problemas de Coração, mortes por descartes, ou seja, pintos com defeitos genéticos ou mortes por pernas quebradas.

O resultado da aplicação desta ferramenta mostra que a mortes por pernas foram pequenas e com pouca variabilidade no período. A morte por coração foi maior no final do período, as mortes sem causas específicas e os descartes variaram bastante no processo, com ênfase no início do processo, ou seja, 15 dias após e no final do processo.

As mortes por Coração justifica-se em razão que ocorrem com mais frequência justamente quando o ganho de peso é mais constante e quando o frango possui maior percepção do calor dentro do aviário, já que o espaço entre eles diminuem.

Para garantir os resultados utilizou-se o Gráfico de Pareto para separar as causas vitais das triviais, conforme Gráfico 3.

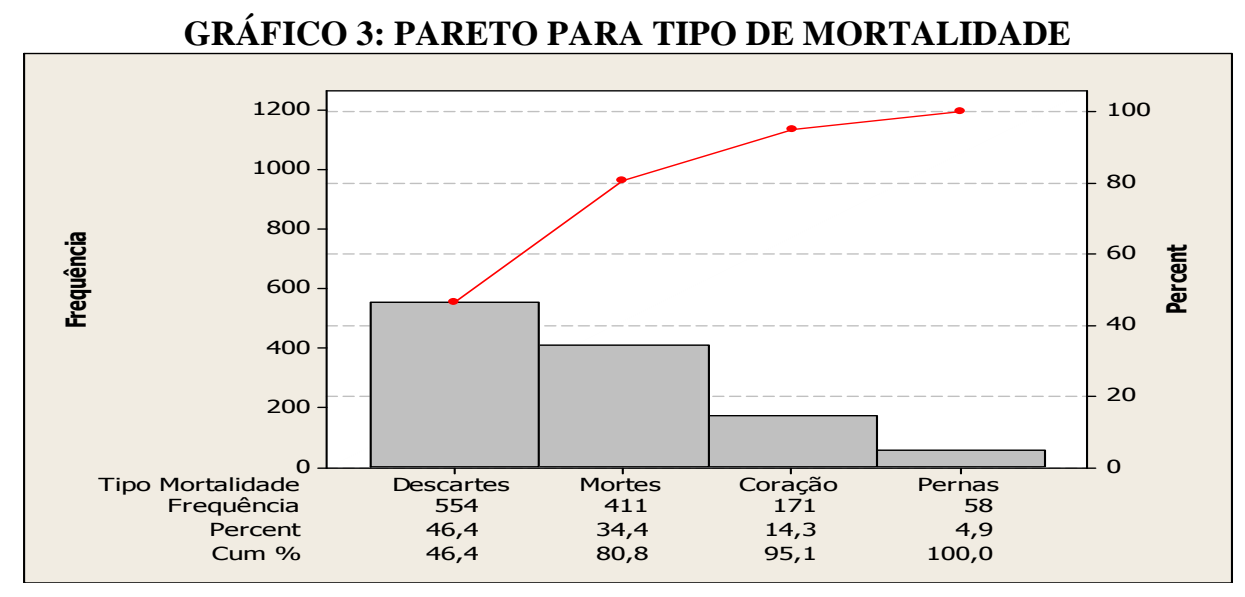

Fonte: Dados da pesquisa 


\section{ReLAInEF}

Nota-se que a principal causa de morte foi o descarte com 46,4\% (554 ocorrências), seguido de mortes sem causa com 34.4\% (411 ocorrências), coração e pernas são menos significantes se comparados com os dois primeiros tipos que perfazem $80,8 \%$ do total de mortes. Assim sendo, vale a pena começar investigar primeiramente o maior problema da mortalidade que é o Descarte. Para tanto, foi realizado um brainstorming com o proprietário do aviário e especialista na área, buscando verificar as causas possíveis que provocam o número elevado de descartes. O resultado está apresentado no Gráfico 4.

A partir das causas utilizou-se o método de
Indução, Dedução e Verificação de cada item, provocando cada causa em razão de sua significância para o problema. Os resultados obtidos com o diagrama de causa-efeito foram os seguintes: O problema provavelmente deve estar afeto à:

a) Genética dos pintos;

b) Distancia percorrida pelo frango do incubatório até o aviário, pode ter ocorrido desidratação $(280 \mathrm{~km})$;

c) Matrizes muitos nova.

Os argumentos acima podem justificar o desalinhamento entre a média e mediana, identificados no histograma constante no Gráfico 5.

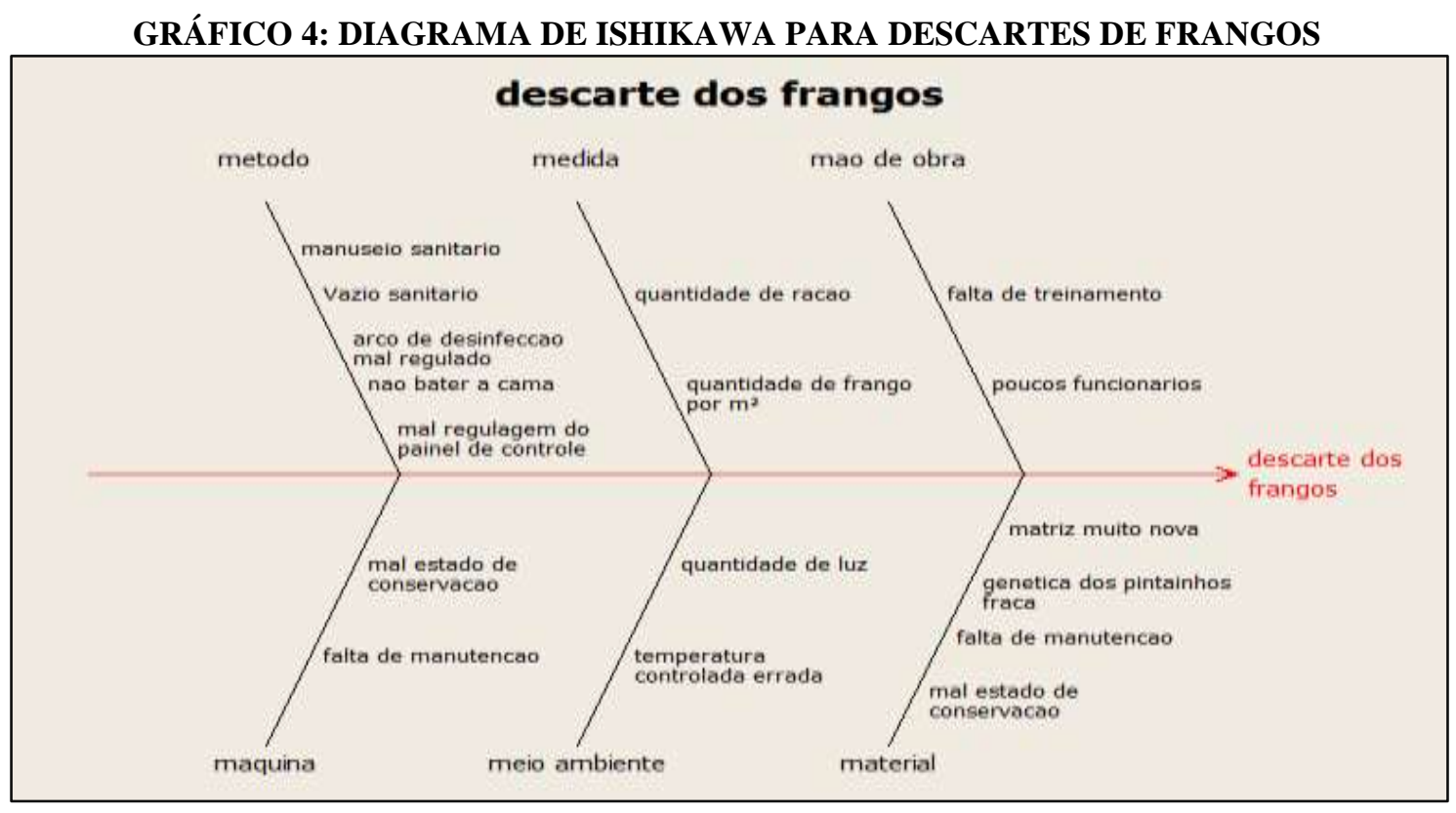

Fonte: Dados da pesquisa 


\section{ReLAInEP}

GRÁFICO 5: HISTOGRAMA PARA DESCARTES

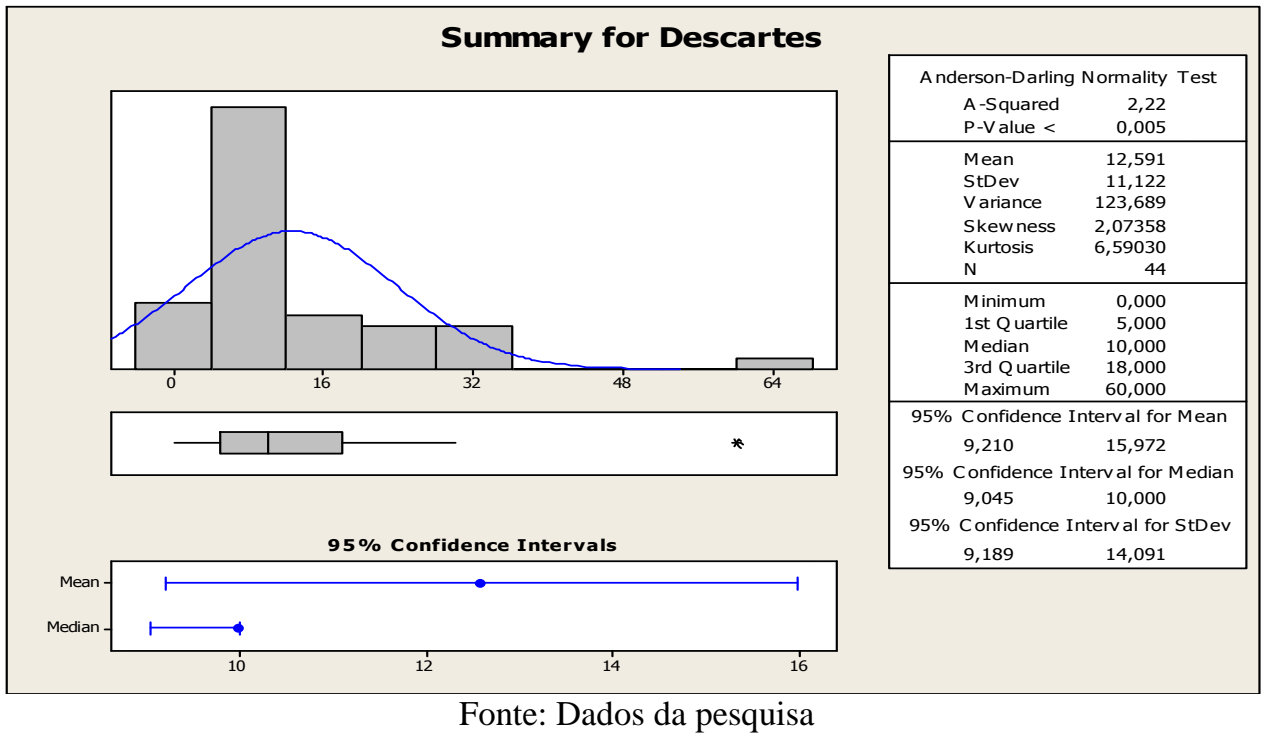

No entanto, as principais causas destacadas são processos realizados pela agroindústria e estão fora de controle do aviário. Estas causas estão atreladas ao contrato que integrado (aviário) e integrador estabelecem. A indústria entrega os pintainhos ao aviário cuja linhagem é escolhida por ela, assim como todo o processo de escolha de matrizes e incubação do ovo é realizado por ela.

Quando causas externas afetam o negócio deve-se examinar os contratos, assim como a viabilidade de mudança de fornecedor (KOTLER; ARMSTRONG, 1998). Diante disso, sugere-se utilizar as ações para solução do problema apresentadas no Gráfico 6.

\section{GRÁFICO 6: POSSÍVEIS AÇÕES PARA SOLUÇÃO DO PROBLEMA}

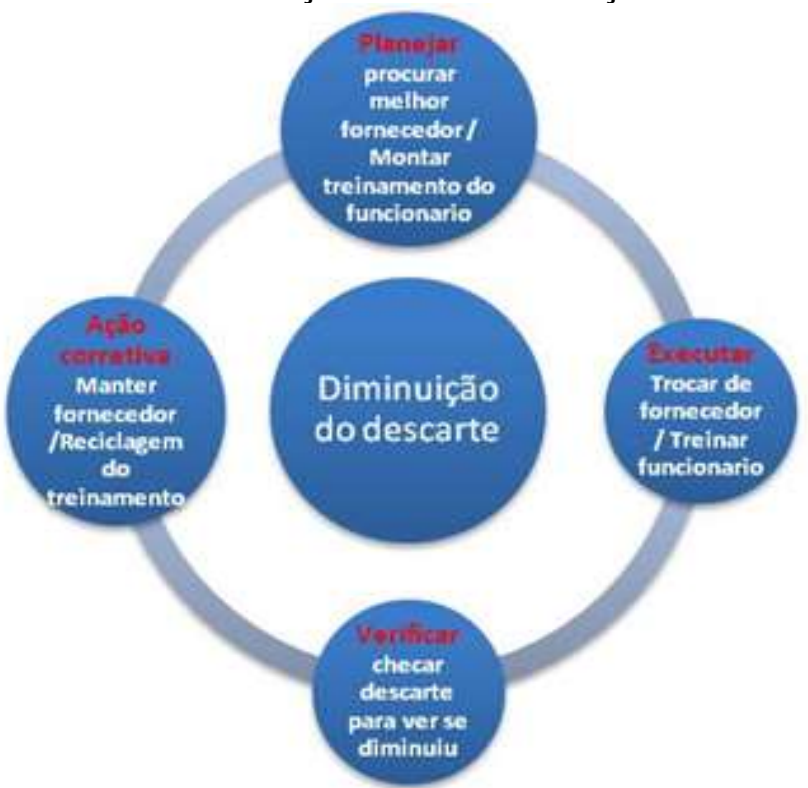

Fonte: Adaptado do ciclo de PDCA 
A sugestão é utilizar a metodologia PDCA por meio de ações e aplicação de ferramentas após tomar decisão de troca ou manutenção do fornecedor. As diversas ações estão atreladas também ao treinamento dos funcionários para diminuição dos descartes para detectar com maior precisão a causa das mortes, que podem modificar o quadro existente e surjam ações que possam ser controladas.

\section{Conclusões}

A partir deste trabalho foi possível vivenciar a utilização das principais ferramentas da qualidade, para solução do problema de descarte e melhorar o processo produtivo de frangos do aviário do sítio Boa Esperança.

Pode-se perceber também o quão importante e eficiente estas ferramentas podem ser, pois a identificação do problema de descarte só foi possível graças ao diagrama de Pareto, bem como as possíveis causas foram possíveis por meio do diagrama de causa-efeito.

A conclusão obtida quanto às causas que provocam a mortalidade dos frangos foram entendidas como variáveis incontroláveis, ou seja, aquelas sobre as quais a empresa não tem pleno poder de influência, necessitando adaptar seus processos às mudanças dessas mesmas variáveis. A propriedade deve considerar o que não pode modificar ou controlar, como a mudança para um fornecedor que possua matrizeiro mais próximo, ou solicitar ao fornecedor atual estudos sobre os problemas de genética ou a utilização de matrizes novas para a produção dos ovos.

Cabe ressaltar que a necessidade de adaptabili- dade leva a crer que a propriedade deve-se ajustar às questões ambientais para continuar no mercado e não simplesmente para produzir muito mais. Trata-se de uma questão mais complexa de relacionamentos de longo prazo.

Espera-se que este estudo forneça subsídio para busca de solução de problemas em diversos setores, lembrando que ferramentas podem e devem ser adicionadas para maior precisão da informação.

\section{Referências}

ABEPRO - Associação Brasileira de Engenharia de Produção. Áreas da Engenharia de Produção. Disponível em < http://www.abepro.org.br>. Acessado em 11 de setembro de 2013.

ABREU, G. PAULO.; ABREU, V. MARIA. Os desafios da ambiência sobre os sistemas de aves no Brasil. 2011. Disponível em: $<$ http: / / ainfo.cnptia.embrapa.br/digital/bitstrea $\mathrm{m} /$ item/42704/1/os-desafios-da-ambienciasobre-os-sistemas.pdf $>$ acessado em: 20 de setembro 2013.

CHASE, R. B.; JACOBS, F. R.; AQUILANO, N. J. Administração da Produção para a Vantagem competitiva. 10 ed., São Paulo: ARTMED, 2004.

GODOY, L. A. Folha de Verificação - Ferramenta da Qualidade, 2009. Disponível em: <http://www.cedet.com.br/index.php?/Oque-e/Gestao-da-Qualidade/folha-deverificacao-ferramenta-da-qualidade.html> .Acesso em : 07 de junho de 2013.

HEINZEN, F. L. A realidade em uma pequena empresa da avicultura catarinense, 2006. Disponível

em:<http://www.agencia.cnptia.embrapa.br/R eposito-

rio/a_realidade_em_uma_pequena_empresa_da _avicultura_catarinense_000fy1 kefvx02wx5ok0 pvo4k3lkk9y5b.pdf $>$. Acesso em 26 de setembro de 2013.

KOTLER, Philip; ARMSTRONG, Gary. Princí- 
pios de Marketing. 8. ed. Rio de Janeiro: Prentice-Hall, 1998.

MONTGOMERY C. D. Introdução ao controle Estatístico da Qualidade. Rio de Janeiro: LTC, 2004.

O GLOBO - Produção de carne de Frango no Brasil crescer $80 \%$ em dez anos estima governo. 2013. Disponível em: <http://oglobo.globo.com/economia/produca o-de-carne-de-frango-no-brasil-deve-crescer-80em-dez-anos-estima-governo-7998879> Acesso em: 20 de setembro de 2013.

PALADINI, E. P. Gestão da Qualidade - Teoria e Prática. São Paulo: Atlas, 2000.

QUALIDADE BRASIL - O que é Histograma, $2011 . \quad$ Disponível em:<http://www.qualidadebrasil.com.br/notic ia/o_que_e_histograma $>$ Acesso em: 07 de junho de 2013.

SANTOS, C. ANTONIO; RICHETTI, ANTÔNIO. $O$ sistema integrado de produção de frango de corte em minas gerais: uma análise sob a ótica da ECT. 2000. Disponível em: <http:/ / revista.dae.ufla.br/index.php/ora/arti cle/viewFile/282/280> Acesso em 28 de setembro 2013.

SLACK, N.; CHAMBER, S.; HARDLAND, C.; HARRISON, A.; JOHNSTON, R. Administração da Produção. São Paulo: Atlas, 1999. 